San Antonio Review • San Antonio Review (Issue 2 | Winter 2019)

\title{
Neptune's Son
}

\section{Daniel Edward Moore}

Published on: Jun 19, 2019

Updated on: Aug 02, 2020

License: Creative Commons Attribution 4.0 International License (CC-BY 4.0). 


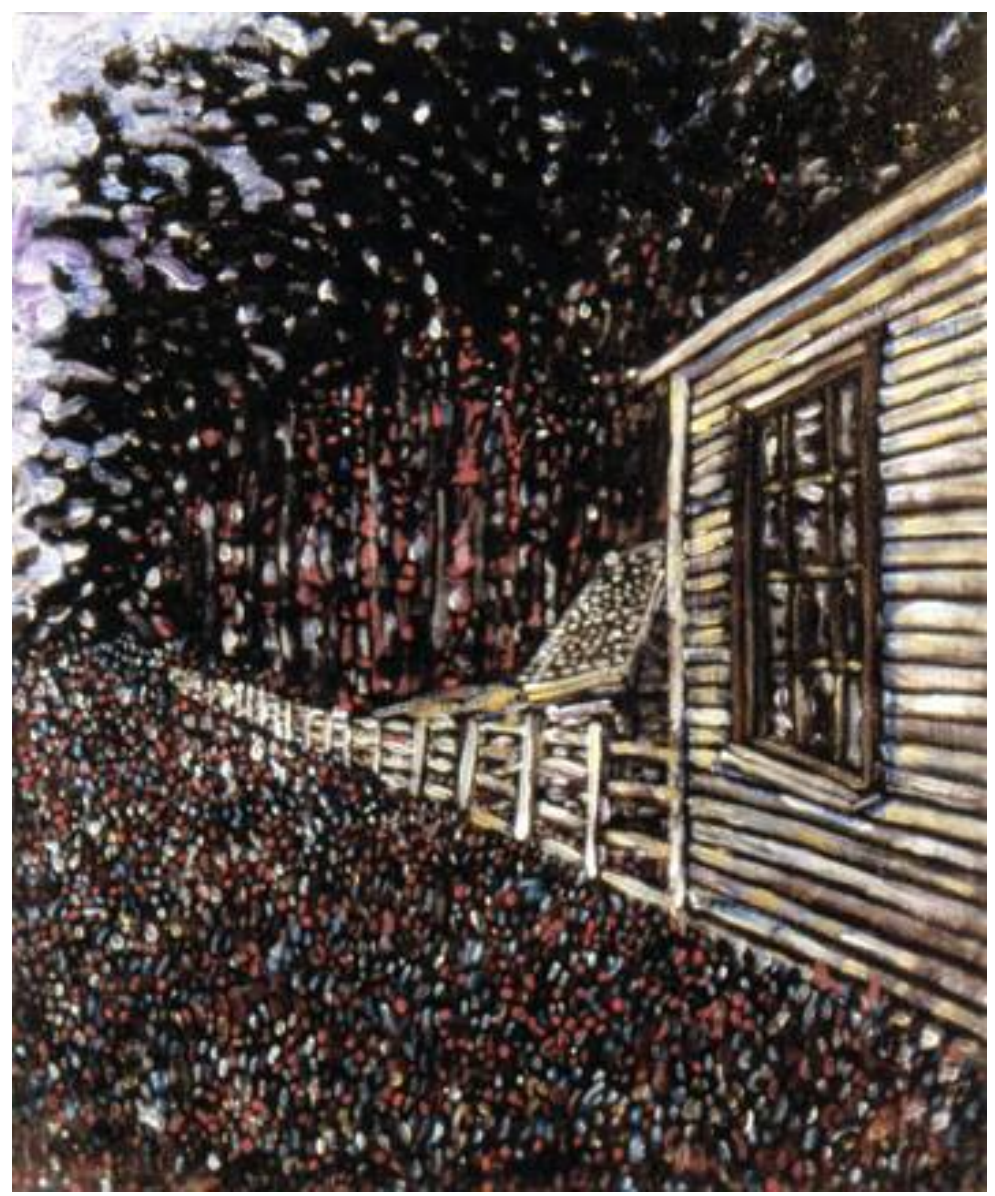

Image: Painting by Brianna Keeper

Last night, a boy again,

fell from Ohio's steamy sky,

shedding his ivory northwest skin

into Appalachia's coal-stained hands

on the river's muddy arms.

It took Alaska's steel grey wings

to lamp his face with fireflies.

Morse code flashed above cottonmouths

cruising the creek for dinner

as frogs folded their legs in prayer,

sparing themselves from a three-prong gig,

dripping with summer's hunger. 
This is why Neptune's son,

wounded the side of a hill with forts,

his ribs splayed by a rocky world

nothing red \& beating could save,

nothing compared to the floodwall's face washed in the beauty of time.

Daniel Edward Moore lives in Washington on Whidbey Island with the poet, Laura Coe Moore. His poems have appeared in Spoon River Poetry Review, Columbia Journal, Cream City Review, Western Humanities Review and others. His chapbook Boys is forthcoming from Duck Lake Books in February 2020. His first book, Waxing the Dents, was a finalist for the Brick Road Poetry Book Prize and will be released in April 2020. 